\title{
Effects of changes in isotopic baselines on the evaluation of food web structure using isotopic functional indices
}

\author{
Simon Belle ${ }^{\text {Corresp., } 1,2}$, Gilbert Cabana ${ }^{2}$ \\ ${ }^{1}$ Department of Aquatic Sciences and Assessment, Swedish University of Agricultural Sciences, Uppsala, Sweden \\ ${ }^{2}$ Centre de Recherche sur les Interactions Bassins Versants-Ecosystèmes Aquatiques (RIVE), Université du Québec à Trois-Rivières, Trois-Rivières, Canada \\ Corresponding Author: Simon Belle \\ Email address: simon.belle@slu.se
}

Background. This study aimed to assess whether ecological inferences from isotopic functional indices (IFIs) are impacted by changes in isotopic baselines in aquatic food webs. We used sudden $\mathrm{CO}_{2}$ outgassing and associated shifts in DIC- ${ }^{13} \mathrm{C}$ brought by waterfalls as an excellent natural experimental set-up to quantify impacts of changes in algal isotopic baselines on ecological inferences from IFIs.

Methods. Carbon $\left(\delta^{13} \mathrm{C}\right)$ and nitrogen $\left(\delta^{15} \mathrm{~N}\right)$ stable isotopic ratios of invertebrate communities sharing similar structure were measured at above- and below-waterfall sampling sites from five rivers and streams in Southern Quebec (Canada). For each sampled invertebrate community, the six Layman's IFls were then calculated in the $\delta$-space $\left(\delta^{13} \mathrm{C} v s . \delta^{15} \mathrm{~N}\right)$.

Results. As expected, isotopic functional richness indices, measuring the overall extent of community trophic space, were strongly sensitive to changes in isotopic baselines unlike other IFIs. Indeed, other IFIs were calculated based on the distribution of species within $\delta$-space and were not strongly impacted by changes in the vertical or horizontal distribution of specimens in the $\delta$-space. Our results highlighted that IFIs exhibited different sensitivities to changes in isotopic baselines, leading to potential misinterpretations of IFIs in river studies where isotopic baselines generally show high temporal and spatial variabilities. The identification of isotopic baselines and their associated variability, and the use of independent trophic tracers to identify the actual energy pathways through food webs must be a prerequisite to IFIs-based studies to strengthen the reliability of ecological inferences of food web structural properties. 
1 Effects of changes in isotopic baselines on the

2 evaluation of food web structure using isotopic

\section{3 functional indices.}

4 BELLE Simon ${ }^{12}$, CABANA Gilbert ${ }^{1}$.

$5{ }^{1}$ Centre de Recherche sur les Interactions Bassins Versants-Ecosystèmes Aquatiques (RIVE),

6 Université du Québec à Trois-Rivières, Trois-Rivières, CANADA

72 Department of Aquatic Sciences and Assessment, Swedish University of Agricultural Sciences,

8 Uppsala, SWEDEN

9 E-mail: simon.belle@slu.se

10 Key-words: Aquatic food webs; Trophic structure; Stable isotopes; Waterfalls. 


\section{Abstract}

14 Background. This study aimed to assess whether ecological inferences from isotopic functional

15 indices (IFIs) are impacted by changes in isotopic baselines in aquatic food webs. We used sudden

$16 \mathrm{CO}_{2}$-outgassing and associated shifts in DIC- $\delta^{13} \mathrm{C}$ brought by waterfalls as an excellent natural

17 experimental set-up to quantify impacts of changes in algal isotopic baselines on ecological

18 inferences from IFIs.

19 Methods. Carbon $\left(\delta^{13} \mathrm{C}\right)$ and nitrogen $\left(\delta^{15} \mathrm{~N}\right)$ stable isotopic ratios of invertebrate communities sharing similar structure were measured at above- and below-waterfall sampling sites from five rivers and streams in Southern Quebec (Canada). For each sampled invertebrate community, the six Layman's IFIs were then calculated in the $\delta$-space $\left(\delta^{13} \mathrm{C} v s . \delta^{15} \mathrm{~N}\right)$.

23 Results. As expected, isotopic functional richness indices, measuring the overall extent of community trophic space, were strongly sensitive to changes in isotopic baselines unlike other IFIs. Indeed, other IFIs were calculated based on the distribution of species within $\delta$-space and were not strongly impacted by changes in the vertical or horizontal distribution of specimens in the $\delta$-space. Our results highlighted that IFIs exhibited different sensitivities to changes in isotopic baselines, leading to potential misinterpretations of IFIs in river studies where isotopic baselines generally show high temporal and spatial variabilities. The identification of isotopic baselines and their associated variability, and the use of independent trophic tracers to identify the actual energy pathways through food webs must be a prerequisite to IFIs-based studies to strengthen the

32 reliability of ecological inferences of food web structural properties. 
33

34

\section{Introduction}

Stable isotopes analysis, mainly those of carbon and nitrogen, of aquatic consumers is a common technique to provide quantitative and qualitative measurements of energy flows in food webs (Cabana and Rasmussen 1996; Post et al. 2002; Vander Zanden et al. 2016). Consumer isotopic ratios are often represented in a $\delta$-space (i.e. $\delta^{13} \mathrm{C}-\delta^{15} \mathrm{~N}$ biplot), where species trophic interactions can be assessed using a large variety of analytical tools (Layman et al. 2012). Among them, isotopic functional indices (IFIs) are based on the distribution and the dispersion of species in $\delta$ space and have been developed to calculate measures of trophic structure of food webs (Layman et al. 2007; Jackson et al. 2011; Cucherousset and Villéger 2015). Briefly, IFIs allow to infer food web structural properties, and can be grouped according to three major components of trophic diversity. First, isotopic functional richness providing a quantitative indication of the extent of isotopic space of the entire community (Layman et al. 2007; Jackson et al. 2011). Secondly, isotopic functional divergence providing information on the average degree of trophic diversity within a $\delta$-space (Layman et al. 2007), and thirdly, isotopic functional evenness quantifies the regularity in species distribution and may also be seen as an indicator of trophic redundancy in food webs (Layman et al. 2007; Rigolet al. 2013).

The IFI concept is, however, based on two main assumptions: that two close species have similar role in food webs; and that isotopic metrics are good proxies of food web structural properties (Layman et al. 2007), but too few empirical studies have been conducted to evaluate the validity of these underlying assumptions (Syväranta et al. 2013; Jabot et al. 2017). Several authors have, however, pointed out that overlaps and variabilities in isotopic baselines could be major pitfalls of IFIs and hamper identification of actual food web structure (Hoeinghaus and Zeug 2008; Jabot et 
56 al. 2017), but very few studies have empirically tested for the sensitivity of IFIs to these issues

57 (Jackson et al. 2011). Moreover, differences in IFIs sensitivities to changes in isotopic baselines

58 could be inherently driven by differences in calculation methods: being higher for IFIs based on

59 dispersion of species in the $\delta$-space than for others based on their distribution. For instance, several

60 authors have suggested that isotopic functional richness indices (i.e. measuring species dispersion

61 in the $\delta$-space) are strongly influenced by changes in ranges of consumers $\delta^{13} \mathrm{C}$ and $\delta^{15} \mathrm{~N}$ values

62 (Brind'Amour and Dubois 2013; Syvaränta et al. 2013), and ecological inferences of food web

63 structural properties from these scale-dependent IFIs are therefore highly sensitive to changes in

64 isotopic baselines.

65 Carbon of aquatic consumers sustained by autochthonous food resources (i.e., algae) is derived 66 from the fixation by autochthonous primary producers of dissolved inorganic carbon (DIC) during

67 photosynthesis. In river ecosystems, many biological and biochemical processes (i.e. respiration, 68 water flow velocity, etc.) can influence DIC- $\delta^{13} \mathrm{C}$ values (see also Finlay 2003), leading to strong

69 spatial/temporal variability in algal $\delta^{13} \mathrm{C}$ values (France and Cattaneo 1998; Finlay 2001;

70 Rasmussen 2010). Due to this large variability in isotopic baseline over time/space, different diets

71 could lead to similar isotopic ratios of aquatic consumers, and conversely same diets could have

72 different isotopic ratios. Changes in isotopic ratios of basal food resources can thus lead to potential

73 misinterpretations of IFIs in river studies comparing food webs across sites and/or over time, and

74 complementary empirical studies are needed to better assess whether ecological inferences from

75 IFIs are impacted by variabilities in isotopic baselines.

76 Artificial variability in river algal $\delta^{13} \mathrm{C}$ values can be acquired by manipulating $\mathrm{DIC}-\delta^{13} \mathrm{C}$ values

77 (Cole et al. 2002). In that vein, artificial tracer studies (i.e., ${ }^{13} \mathrm{C}$-tracer addition experiments) have

78 been conducted in small streams to induce changes in isotopic baselines of algal food resources 
and track the fate of algal biomass in stream food webs (Hotchkiss and Hall 2015), but this strategy appeared, however, not suitable for larger ecosystems (Sánchez-Carrillo and Álvarez-Cobelas 2017). Waterfalls decrease the thickness of the boundary layer at the air/water interface, leading to massive gaseous exchanges with the atmosphere over short distances (Chen et al. 2004; Teodoru et al. 2015; Leibowitz et al. 2017). Hence, waterfalls induce $\mathrm{CO}_{2}$-outgassing and associated shifts in DIC- $\delta \delta^{13} \mathrm{C}$ values in acidic running waters where carbonate dissolution cannot compensate for the loss of $\mathrm{CO}_{2}$ (Palmer et al. 2001; Doctor et al. 2008). Rapid degassing and equilibration to atmospheric values and associated shifts in DIC- $\delta^{13} \mathrm{C}$ below waterfalls should induce changes only in algal $\delta^{13} \mathrm{C}$ values, and theoretically not affect isotopic ratios of allochthonous organic matter. As algal production has been shown to be an important source of $\mathrm{C}$ in similar streams/rivers (see also Rasmussen 2010), we expected a shift in scale dependent IFIs linked to a shift in algal $\delta^{13} \mathrm{C}$ values. Therefore, waterfall systems could provide an excellent natural experimental set-up to quantify impacts of changes in isotopic baselines on ecological inferences from IFIs in a range of rivers and streams varying in size.

The aim was to study impacts of changes in isotopic baselines on the evaluation of food web structure using IFIs, and we hypothesized that DIC isotopic shifts brought by $\mathrm{CO}_{2}$-outgassing at waterfall sites should induce changes in food web structure inferences based on IFIs. Similarity in food web structures at above- versus below-waterfall sampling sites from five rivers and streams in Southern Quebec (Canada) were tested by comparing taxonomic composition and $\delta^{15} \mathrm{~N}$ values to assess positioning of trophic guilds. We also compared IFIs (calculated in the $\delta^{13} \mathrm{C}-\delta^{15} \mathrm{~N}$ space) for invertebrate communities at above- and below-waterfall sites, and differences in IFIs within waterfall paired-sites was interpreted as a result of changes in algal isotopic baselines brought by waterfall induced-DIC isotopic shifts. We hypothesized that IFIs exhibit different sensitivities to 
102 changes in isotopic baselines due to calculation methods. IFIs calculated using the dispersion of 103 species in a $\delta$-space (isotopic functional richness) are therefore scale-dependent and should be 104 more sensitive to changes in isotopic baselines than those based on the distribution of species 105 within a $\delta$-space (isotopic functional evenness and diversity).

Material and methods

\section{Site description and sampling protocol}

111 Five waterfalls (with vertical drops ranging from 18 to $72 \mathrm{~m}$ ), from small streams to large rivers

112 (widths ranging from 6 to $50 \mathrm{~m}$ ), were studied in Southern Quebec, Canada (between $46-47^{\circ} \mathrm{N}$ and $72-73^{\circ} \mathrm{W}$ ). Their catchment areas are situated on the Canadian Shield (corresponding to a metamorphic geological formation), making the running water weakly conductive and slightly acidic (ranging from 20 to $50 \mu \mathrm{S} . \mathrm{cm}^{-1}$ with an average $\mathrm{pH}$ value around $6.3 \pm 0.4$ at investigated sites). To use changes in $\mathrm{DIC}-\delta^{13} \mathrm{C}$ values brought by waterfall $\mathrm{CO}_{2}$-outgassing as an integrative indicator of changes in algal isotopic baselines, each site was sampled at two locations immediately upstream and downstream of the waterfall (hereafter above- and below-waterfall), and the maximum distance between the two sampling points was $300 \mathrm{~m}$. Paired sampling locations were also selected to have similar environmental conditions (water velocity, riverbed substrates, water

121 depth, surrounding vegetation cover, canopy cover, etc.). Therefore, as habitat structures in each 122 waterfall paired-sites were similar, food web structures of above- and below-waterfall invertebrate communities were also expected to be similar. 
127 Water chemistry (partial pressure of $\mathrm{CO}_{2}: p \mathrm{CO}_{2}, \mathrm{DIC}-\delta^{13} \mathrm{C}$ ) was measured at each sampling site to 128 characterize biogeochemical effects of waterfalls and quantify expected shifts in algal $\delta^{13} \mathrm{C}$ values. 129 The selected sites were visited between 1 to 2 times in spring and summer (in early May and late 130 June 2016). $p \mathrm{CO}_{2}$ was measured using the headspace method (Campeau and del Giorgio 2014). $13130 \mathrm{~mL}$ of water sample was collected from approximately $10 \mathrm{~cm}$ below the water surface, using a $13260 \mathrm{~mL}$ polypropylene syringe, and $30 \mathrm{~mL}$ of ambient air was added into the syringe to create a 1:1 133 ratio (ambient air: water sample). Then, the syringe was vigorously shaken for 1.5 min to 134 equilibrate the gases in the water and air fractions. $30 \mathrm{~mL}$ of the headspace was then injected into 135 a $40 \mathrm{~mL}$ glass vial, prefilled with saturated $\mathrm{NaCl}$ solution $\left(360\right.$ g. $\mathrm{L}^{-1}$ at $\left.20^{\circ} \mathrm{C}\right)$, through a butyl 136 rubber septum. A second needle was used to evacuate the excess of $\mathrm{NaCl}$ solution. Vials were kept 137 inverted for storage, and headspaces were analysed using a Shimadzu GC-8A Gas Chromatograph 138 with flame ionization detector at University of Quebec at Montreal (Montreal, Canada). $p \mathrm{CO}_{2}$ in water samples was then retrocalculated using the headspace ratio, water temperature and ambient

140 air concentrations of $\mathrm{CO}_{2}$ at studied sites. $p \mathrm{CO}_{2}$ measurements were performed in duplicates for each sampling site. Supersaturation ratios (SR) were also calculated by dividing the gas water 142 partial pressure by the atmospheric $\mathrm{CO}_{2}$ concentration.

143 At each sampling site, $500 \mathrm{~mL}$ of water sample was also collected in duplicates in early May and 144 late June 2016 to analyse DIC- $\delta{ }^{13} \mathrm{C}$. Water samples were filtered at $0.2 \mu \mathrm{m}$ using nitrocellulose 145 membrane filters and stored for a maximum of $72 \mathrm{~h}$ in the dark at $4^{\circ} \mathrm{C}$ until analysis. $150 \mu \mathrm{L}$ of 146 phosphoric acid $\left(\mathrm{H}_{3} \mathrm{PO}_{4} ; 85 \%\right)$ was added into $12.5 \mathrm{~mL}$ amber borosilicate vials to ensure that all 
147 DIC content in the water sample would be converted into $\mathrm{CO}_{2}$. Then, vials were flushed using

148 Helium during $10 \mathrm{~min}$ to ensure a full evacuation of ambient air. $4 \mathrm{~mL}$ of water sample was

149 injected in He-flushed vials through the rubber septa using fine needles, and vials were equilibrated

150 at $20^{\circ} \mathrm{C}$ for $18 \mathrm{~h}$. DIC- $\delta^{13} \mathrm{C}$ was obtained using with a ThermoFinnigan Gas Bench II coupled to an

151 Isotope Ratio Mass Spectrometer (IRMS), and results were expressed as the delta notation with

152 Vienna Pee Dee Belemnite as the standard: $\delta^{13} \mathrm{C}(\%)=\left(\left[\mathrm{R}_{\text {sample }} / \mathrm{R}_{\text {standard }}\right]-1\right) \times 1000$; where $\mathrm{R}=$ $153{ }^{13} \mathrm{C} /{ }^{12} \mathrm{C}$. Sample measurement replications from internal standards $(\mathrm{C} 1=-3.0 \%$, and $\mathrm{C} 5=-22.0$

$154 \%)$ produced analytical errors $(1 \sigma)$ of $\pm 0.3 \%$ o $(n=17)$.

155

\section{Invertebrate sampling and carbon stable isotope}

157

Each sampling station was sampled in early July 2016, and benthic invertebrates were collected in riffle sections using a kick-net $\left(0.1 \mathrm{~m}^{2}, 600 \mu \mathrm{m}\right.$ mesh size $)$. Equal sampling effort was applied to each habitat type within above- and below-waterfall sites. Invertebrate specimens were sorted immediately in the field into taxonomic groups and transported in the dark at $4{ }^{\circ} \mathrm{C}$ back to the laboratory $4-8$ hours later to be frozen at $-20^{\circ} \mathrm{C}$ until analysis. A small isotopic deviation can be observed using this method (see also Feuchtmayr and Grey 2003; Wolf et al. 2016), but we assumed that this effect was the same for all samples. Invertebrates were identified at the genus level (Merritt and Cummins, 1996), and specimens were then classified into different feeding groups as herbivores, detritivores, and predators (Thorp 1991; Merritt and Cummins 1996; Electronic supplementary material S2). Samples were then dried at $60^{\circ} \mathrm{C}$ for $72 \mathrm{~h}$ and ground into 168 fine powder. Carbon $\left(\delta^{13} \mathrm{C}\right)$ and nitrogen $\left(\delta^{15} \mathrm{~N}\right)$ stable isotopic ratios were then analysed using an of Quebec at Trois-Rivieres (Trois-Rivieres, Canada). Results were expressed according to the 
171 delta notation (see above). Sample measurement replications from three internal standards

172 (STD67: $\delta^{13} \mathrm{C}=-37 \%$ and $\delta^{15} \mathrm{~N}=8.6 \%$, UTG40: $\delta^{13} \mathrm{C}=-26.2 \%$ and $\delta^{15} \mathrm{~N}=-4.5 \%$, and BOB1

$173 \delta^{13} \mathrm{C}=-27 \%$ and $\delta^{15} \mathrm{~N}=11.6 \%$ ) produced analytical errors $(1 \sigma)$ of $\pm 0.02 \%$ for $\delta^{13} \mathrm{C}$ values and

$174 \pm 0.2 \%$ for $\delta^{15} \mathrm{~N}$ values $(n=148)$.

175

176

\section{Isotopic functional indices and data analysis}

Non-metric Multidimensional Scaling (NMDS) was used to visualize dissimilarities among/within invertebrate communities at waterfalls sites, and the Bray-Curtis index was used to measure dissimilarities of invertebrate communities based on presence/absence data. T-tests were also performed on trophic guilds $\delta^{15} \mathrm{~N}$ values to compare their trophic positions in food webs at aboveand below-waterfall sites.

Means of $\delta^{13} \mathrm{C}$ and $\delta^{15} \mathrm{~N}$ values of all individuals for each species calculated at each sampling site were used to derive six IFIs following Layman et al. (2007): $\delta^{13} \mathrm{C}$ range (CR), $\delta^{15} \mathrm{~N}$ range (NR), total area of the convex hull encompassing all the observations (TA), mean distance to centroid (CD), mean nearest neighbour distance (MNND) and standard deviation of nearest neighbour distance (SDNND). Layman's IFIs can be grouped into isotopic functional richness (CR, NR and TA); isotopic functional divergence (CD); and isotopic functional evenness (NND and SDNND). As isotopic functional richness indices ( $\mathrm{CR}, \mathrm{NR}$ and $\mathrm{TA})$ provide a quantitative indication of the extent of the isotopic niche space of the entire community and are calculated using the dispersion of species in the $\delta$-space (Layman et al. 2007; Jackson et al. 2011), we hypothesized that those

IFIs should be more sensitive than those based on the distribution of species in the $\delta$-space (CD, MNND and SDNND; Appendix. 1). All indices were calculated using SIAR package for R (Parnell 
194 and Jackson 2013). Principal component analysis (PCA) was also performed to display changes in

195 structural properties of above- and below-waterfall invertebrate communities and provide an 196 overview of relationships between IFIs and changes in DIC- $\delta^{13} \mathrm{C}$ values. All statistical analyses

197 and plots were performed using the R 3.5.2 software (R Core Team 2018).

\section{Results}

200

201

A total of 36 water samples were analysed for $p \mathrm{CO}_{2}$ and DIC- $\delta^{13} \mathrm{C}$. In our study, sampled running 202 waters were slightly acidic (with an average $\mathrm{pH}$ value around $6.3 \pm 0.4$ ) and carbonate dissolution cannot compensate for the loss of $\mathrm{CO}_{2}$. Therefore, waterfalls induced consistent increase in DIC$\delta^{13} \mathrm{C}$ values induced by rapid $\mathrm{CO}_{2}$-outgassing (Fig. 1). Below-waterfall DIC- $\delta^{13} \mathrm{C}$ values were always higher than those of above-waterfall samples, and results showed an average increase of $2.2 \%$ (ranging from $-3.8 \pm 0.2 \%$ to $-0.9 \pm 0.2 \%$; Fig. 1 ). Temporal comparisons between the two sampling periods (early May and late June 2016) revealed strong differences in $p \mathrm{CO}_{2}$ and water temperature (rising from $5.3 \pm 1{ }^{\circ} \mathrm{C}$ in May to $19.3 \pm 2.6^{\circ} \mathrm{C}$ in June), but smaller effects for DIC- $\delta{ }^{13} \mathrm{C}$ values relative to the above- vs. below-waterfall sites (Fig. 1).

Most of the genera caught at each above-waterfall site were also found at below-waterfall sites

211 (Table 1). Bray-Curtis index between each paired waterfall sites ranged 0.13-0.4, whereas the 212 average Bray-Curtis index value calculated among sites was $0.38 \pm 0.09$, suggesting that 213 compositional differences among communities were higher among waterfalls than within each 214 paired-sites, and high similarity of invertebrate community composition of each paired waterfall 215 sites was also further validated through an NMDS plot (Fig 2). Furthermore, the $\delta^{15} \mathrm{~N}$ values of 
216 invertebrate specimens ranged 0.8-10.2 \%o (Fig. 3), and no significant difference was observed for

217 each trophic guild between above- and below-waterfall samples ( $p$-value $>0.05$; Fig. 4). The $\delta^{13} \mathrm{C}$

218 values of invertebrate specimens ranged from $-33.3 \%$ to $-23 \%$ (Fig. 3) and showed consistent

219 increases in $\delta^{13} \mathrm{C}$ values for below-waterfall samples. The $\delta^{13} \mathrm{C}-\delta^{15} \mathrm{~N}$ biplots visually highlighted

220 strong similarities between above- and below-waterfall invertebrate communities, showing large

221 overlaps in isotopic spaces encompassing all species locations (Fig. 3). Large differences in $\delta^{13} \mathrm{C}$

222 values were also observed among trophic guilds (Fig 5).

223 Calculations of IFIs showed notable changes between above- and below-waterfall IFI values (Fig.

224 6). Isotopic functional evenness and divergence indices (SDNND, MNND and CD, respectively)

225 showed relatively small changes between above- and below-waterfall sites (Fig. 6). In contrast,

226 isotopic functional richness indices (mainly TA and especially CR, as expected, but also NR in a

227 lesser extent) followed important changes between above- and below-waterfall sites, and with few

228 exceptions isotopic functional richness indices were lower at below-waterfall sites than at above-

229 waterfall samples (Fig. 6). Principal component analysis (PCA) gave an overview of differences

230 between above- and below-waterfall invertebrate communities and illustrated the overall

231 relationships between all IFIs. The first two PCA axes explained $54.7 \%$ and $29.1 \%$ of the total

232 variance, respectively (Fig. 7.A). The first PCA axis mainly explained isotopic functional

233 divergence and evenness indices (Fig. 7.B), whereas the second PCA axis explained CR and NR

234 (Fig. 7.B). As expected, additional projection of $\mathrm{DIC}-\delta^{13} \mathrm{C}$ values in the factorial map revealed

235 visual correlation with $\mathrm{CR}$ (as $\delta^{13} \mathrm{C}$ range of invertebrate specimens; Fig. 7.B). Overall, PCA1 and

236 PCA2 scores of below-waterfall invertebrate communities were higher than those of above-

237 waterfall communities (Fig. 7.A), suggesting that IFIs values were often lower at below-waterfall

238 sampling sites than at above-waterfall locations. 
240 Discussion

1. Waterfalls, community structure and basal resources

NMDS (Fig. 2) and taxonomic list (Table 1) showed only little changes in taxonomic composition and suggested that compositional differences among communities were higher among waterfalls than within each paired site. Furthermore, no changes in $\delta^{15} \mathrm{~N}$ values of aquatic consumers (Fig.

247 4) were reported suggesting that the analyzed organisms occupied similar trophic positions in the 248 food webs (Cabana and Rasmussen 1996)) and might therefore feed on similar diets above and 249 below the waterfall sites. Therefore, in our study, waterfalls did not significantly impact the food web structure of invertebrate communities, and these results could strengthen previous findings showing the absence of major effect of waterfall on invertebrate community composition in four tropical rivers (Baker et al. 2016).

253 Waterfall $\mathrm{CO}_{2}$-outgassing and associated shift in DIC- $\delta^{13} \mathrm{C}$ values should induce punctual changes in algal $\delta^{13} \mathrm{C}$ values and could also help to decipher the respective contribution of allochthonous and autochthonous carbon to lotic food webs. With few exceptions, $\delta^{13} \mathrm{C}$ values of trophic guilds were higher at below-waterfall sites than those of above-waterfall samples (Fig. 3), supporting the

257 view that aquatic invertebrates mainly feed on in-stream algae (Tanentzap et al. 2017). However, differences among trophic guilds observed in our study might also suggest varying reliance on algae (Fig 5). Surprisingly, large isotopic shifts were also observed for detritivores (but were in 
261 sources for these organisms theoretically relying on detritus (Fig. 5; McNeely et al. 2006).

262 Therefore, our study could support the hypothesis of the prevalence of autochthony in river and

263 stream food webs (Brett et al. 2017; Tanentzap et al. 2017) but could also emphasize the issue of

264 trait plasticity for inveterate leading to differences between actual and theoretical feeding habits.

2. Sensitivity of IFI to changes in isotopic baselines

IFIs have become increasingly used in aquatic ecology (Olsson et al. 2009; Abrantes et al. 2014;

Dézerald et al. 2018; Burdon et al. 2019), but IFI concept mainly relies on untested assumptions.

In this study, we consider waterfall systems as a natural experimental set-up to quantify impacts $\mathrm{CO}_{2}$-outgassing and associated shift in DIC- $\delta^{13} \mathrm{C}$ values should induce punctual changes in algal $\delta^{13} \mathrm{C}$ values and therefore help to understand how changes in isotopic baselines impact upon IFIs.

274 Notable differences in in the expected direction in IFI values were reported between above- and below-waterfall sites (Fig. 6), and changes were likely driven by shifts in DIC- $\delta^{13} \mathrm{C}$ values (Fig. 7.B). Isotopic functional evenness and divergence indices (CD, SDNND and MNND) were only slightly impacted by changes in isotopic baselines (Fig. 6). Indeed, those indices were calculated

278 based on the distribution of species in the $\delta$-space (Layman et al. 2007), and ecological inferences were therefore not strongly impacted by changes in the vertical or horizontal distribution of specimens in the isotopic space. In contrast, isotopic functional richness indices (CR, NR and TA), calculated on species dispersion in the $\delta$-space and providing a quantitative indication of the extent

282 of isotopic niche space of the entire community, were strongly influenced by changes in algal $\delta^{13} \mathrm{C}$ 
283 values (Figs. 6 and 7). Moreover, differences in CR, NR and TA values between above- and below-

284 waterfall sites often exceeded the range of changes previously reported in literature (Rigolet et al.

285 2015). These results could strengthen previous findings that these indices are very sensitive to

286 changes in ranges of consumers $\delta^{13} \mathrm{C}$ and $\delta^{15} \mathrm{~N}$ values (Brind' Amour and Dubois 2013; Syvaränta

287 et al. 2013). Hence, isotopic functional richness indices (CR, NR and TA) might be frequently

288 misinterpreted in river studies comparing food webs across sites and/or over time with fluctuating

289 isotopic baselines.

290 Our study suggested that the reliability of IFI inferences can be strengthened by identifying

291 changes in IFIs driven by variability in isotopic baselines. In that vein, different propositions have

292 already been made in the literature to improve the understanding of food web structure and

293 resource partitioning in consumers (e.g. Jabot et al. 2017). The most promising approach likely

294 consists of increasing the number of isotopes studied (like hydrogen and sulphur: Doucett et al.

295 2007; Proulx and Hare 2014) and including other types of data (such as gut content, fatty acids

296 contents or compound specific isotope analysis). Indeed, the combination of these complementary

297 proxies will provide new insights on actual energy pathways through food webs. By enabling a

298 better understanding of trophic interactions in food webs, future IFI-based studies will contribute 299 to better document food web structural properties.

301 Conclusion

303 Our study demonstrated that changes in isotopic baselines can impact the evaluation of river food 304 web structure using IFIs, but these effects depended on IFI types (i.e. being higher for IFIs 
305

306

307

308

309

310

311

312

313

314

315

316

317

318

319

320

321

322

323

324

325

326

measuring species distribution in the $\delta$-space than for other IFIs), leading to potential misinterpretations of IFIs in river studies where isotopic baselines generally show high temporal and spatial variabilities. The identification of isotopic baselines and their associated variability, and the use of independent trophic tracers to identify the actual energy pathways through food webs must be a prerequisite to IFIs-based studies to strengthen the reliability of ecological inferences of food web structural properties.

\section{Acknowledgement}

Financial support was provided by the Conseil Régional de Franche-Comté and the National Research Council of Canada. Special thanks are addressed to Dany Bouchard (UQTR, Canada) for technical assistance during stable isotopes analyses. We also thank Micheline Bertrand and Pauline Jeanneret for their help during fieldwork.

\section{References}

Abrantes, K. G., Barnett, A., \& Bouillon, S. (2014). Stable isotope-based community metrics as a tool to identify patterns in food web structure in east African estuaries. Functional Ecology, 28(1), 270-282. doi:10.1111/1365-2435.12155

Baker, K., Chadwick, M. A., Wahab, R. A., \& Kahar, R. (2016). Benthic community structure and ecosystem functions in above- and below-waterfall pools in Borneo. Hydrobiologia, 381(1), 307322. doi:10.1007/s10750-016-2975-4 
327 Brett, M. T., S. E. Bunn, S. Chandra, A. W. E. Galloway, F. Guo, M. J. Kainz, P. Kankaala, D. C. 328 P. Lau, T. P. Moulton, M. E. Power, J. B. Rasmussen, S. J. Taipale, J. H. Thorp, \& J. D. Wehr, 329 (2017). How important are terrestrial organic carbon inputs for secondary production in freshwater 330 ecosystems? Freshwater Biology, 62(5), 833-853. doi: 10.1111/fwb.12909

331 Burdon, F. J., McIntosh, A. R., \& Harding, J. S. (n.d.). Mechanisms of trophic niche compression: 332 Evidence from landscape disturbance. Journal of Animal Ecology, n/a(n/a). doi: 10.1111/1365$333 \quad 2656.13142$

334 Cabana, G., \& Rasmussen, J. B. (1996). Comparison of aquatic food chains using nitrogen 335 isotopes. Proceedings of the National Academy of Sciences, 93(20), 10844-10847.

336 Campeau, A., \& Del Giorgio, P. A. (2014). Patterns in $\mathrm{CH}_{4}$ and $\mathrm{CO}_{2}$ concentrations across boreal 337 rivers: Major drivers and implications for fluvial greenhouse emissions under climate change 338 scenarios. Global Change Biology, 20(4), 1075-1088. doi:10.1111/gcb.12479

339 Chen, J., Zhang, D. D., Wang, S., Xiao, T., \& Huang, R. (2004). Factors controlling tufa deposition 340 in natural waters at waterfall sites. Sedimentary Geology, 166(3), 353-366. 341 doi:10.1016/j.sedgeo.2004.02.003

342 Cole, J. J., Carpenter, S. R., Kitchell, J. F., \& Pace, M. L. (2002). Pathways of organic carbon 343 utilization in small lakes: Results from a whole-lake ${ }^{13} \mathrm{C}$ addition and coupled model. Limnology 344 and Oceanography, 47(6), 1664-1675. doi:10.4319/1o.2002.47.6.1664

345 Cucherousset, J., \& Villéger, S. (2015). Quantifying the multiple facets of isotopic diversity: new 346 metrics for stable isotope ecology. Ecological Indicators, 56, 152-160. 347 doi:10.1016/j.ecolind.2015.03.032

348 Dézerald, O., D. S. Srivastava, R. Céréghino, J.-F. Carrias, B. Corbara, V. F. Farjalla, C. Leroy, 349 N. A. C. Marino, G. C. O. Piccoli, B. A. Richardson, M. J. Richardson, G. Q. Romero, \& A. L. 350 González, (2018). Functional traits and environmental conditions predict community isotopic 351 niches and energy pathways across spatial scales. Functional Ecology, 0(0). doi:10.1111/1365$352 \quad 2435.13142$

353 Doctor, D. H., Kendall, C., Sebestyen, S. D., Shanley, J. B., Ohte, N., \& Boyer, E. W. (2008). 354 Carbon isotope fractionation of dissolved inorganic carbon (DIC) due to outgassing of carbon 355 dioxide from a headwater stream. Hydrological Processes, 22(14), 2410-2423. 356 doi:10.1002/hyp.6833

357 Doucett, R. R., Marks, J. C., Blinn, D. W., Caron, M., \& Hungate, B. A. (2007). Measuring 358 terrestrial subsidies to aquatic food webs using stable isotopes of hydrogen. Ecology, 88(6), 15873591592. 
360 Feuchtmayr, H., \& Grey, J. (2003). Effect of preparation and preservation procedures on carbon 361 and nitrogen stable isotope determinations from zooplankton. Rapid Communications in Mass 362 Spectrometry, 17(23), 2605-2610. doi:10.1002/rcm.1227

363 Finlay, J. C. (2001). Stable-carbon-isotope ratios of river biota: implications for energy flow in 364 lotic food webs. Ecology, 82(4), 1052-1064.

Finlay, J. C. (2003). Controls of Streamwater Dissolved Inorganic Carbon Dynamics in a Forested Watershed. Biogeochemistry, 62(3), 231-252.

367

368

369

370

371

372

373

374

375

376

377

378

379

380

381

382

383

384

385

386

387

388

389

390

391

392

France, R., \& Cattaneo, A. A. (1998). $\delta^{13} \mathrm{C}$ variability of benthic algae: effects of water colour via modulation by stream current. Freshwater Biology, 39(4), 617-622. doi:10.1046/j.13652427.1998.00307.x

Hotchkiss, E. R., \& Hall, R. O. (2015). Whole-stream ${ }^{13} \mathrm{C}$ tracer addition reveals distinct fates of newly fixed carbon. Ecology, 96(2), 403-416. doi:10.1890/14-0631.1

Hoeinghaus, D. J., \& Zeug, S. C. (2008). Can stable isotope ratios provide for community-wide measures of trophic structure? Comment. Ecology, 89(8), 2353-2357. doi:10.1890/07-1143.1

Jabot, F., Giraldo, C., Lefebvre, S., \& Dubois, S. (2017). Are food web structures well represented in isotopic spaces? Functional Ecology, 31(10), 1975-1984. doi:10.1111/1365-2435.12895

Jackson, A. L., Inger, R., Parnell, A. C., \& Bearhop, S. (2011). Comparing isotopic niche widths among and within communities: SIBER - Stable Isotope Bayesian Ellipses in R. Journal of Animal Ecology, 80(3), 595-602. doi:10.1111/j.1365-2656.2011.01806.x

Layman, C. A., M. S. Araujo, R. Boucek, C. M. Hammerschlag-Peyer, E. Harrison, Z. R. Jud, P. Matich, A. E. Rosenblatt, J. J. Vaudo, L. A. Yeager, D. M. Post, \& S. Bearhop, (2012). Applying stable isotopes to examine food-web structure: an overview of analytical tools. Biological Reviews, 87(3), 545-562. doi:10.1111/j.1469-185X.2011.00208.x

Layman, C. A., Arrington, D. A., Montaña, C. G., \& Post, D. M. (2007). Can stable isotope ratios provide for community-wide measures of trophic structure? Ecology, 88(1), 42-48. doi:10.1890/0012-9658(2007)88[42:CSIRPF]2.0.CO;2

Leibowitz, Z. W., Brito, L. A. F., De Lima, P. V., Eskinazi-Sant'Anna, E. M., \& Barros, N. O. (2017). Significant changes in water $\mathrm{pCO}_{2}$ caused by turbulence from waterfalls. Limnologica Ecology and Management of Inland Waters, 62, 1-4. doi:10.1016/j.limno.2016.09.008

McNeely C., Clinton S.M. \& Erbe J.M. (2006) Landscape variation in C sources of scraping primary consumers in streams. Journal of the North American Benthological Society 25, 787-799.

Merritt, R. W., \& Cummins, K. W. (1996). An Introduction to the Aquatic Insects of North America. Kendall/Hunt Publishing Company. 
393 Olsson, K., Stenroth, P., Nyström, P., \& Granéli, W. (2009). Invasions and niche width: does niche 394 width of an introduced crayfish differ from a native crayfish? Freshwater Biology, 54(8), 1731395 1740. doi:10.1111/j.1365-2427.2009.02221.x

396 Palmer, S. M., Hope, D., Billett, M. F., Dawson, J. J. C., \& Bryant, C. L. (2001). Sources of organic 397 and inorganic carbon in a headwater stream: Evidence from carbon isotope studies. 398 Biogeochemistry, 52(3), 321-338. doi:10.1023/A:1006447706565

399 Parnell, A. and Jackson, A. (2013). siar: Stable Isotope Analysis in R. R package version 4.2. 400 https://CRAN.R-project.org/package=siar.

401 Post, D. M. (2002). Using stable isotopes to estimate trophic position: models, methods, and 402 assumptions. Ecology, 83(3), 703-718.

403 Proulx, I., \& Hare, L. (2014). Differences in feeding behaviour among Chironomus species 404 revealed by measurements of sulphur stable isotopes and cadmium in larvae. Freshwater Biology, 405 59(1), 73-86. doi:10.1111/fwb.12247

406 R Core Team. (2018). R: A language and environment for statistical computing. R Foundation for 407 Statistical Computing, Vienna, Austria. ISBN 3-900051-07-0, URL http://www.R-project.org

408 Rasmussen, J. B. (2010). Estimating terrestrial contribution to stream invertebrates and periphyton 409 using a gradient-based mixing model for $\delta^{13}$ C. Journal of Animal Ecology, 79(2), 393-402. 410 doi:10.1111/j.1365-2656.2009.01648.x

411 Rigolet, C., Thiébaut, E., Brind'Amour, A., \& Dubois, S. F. (2015). Investigating isotopic 412 functional indices to reveal changes in the structure and functioning of benthic communities. 413 Functional Ecology, 29(10), 1350-1360. doi:10.1111/1365-2435.12444

414 Sánchez-Carrillo, S., \& Álvarez-Cobelas, M. (2017). Stable isotopes as tracers in aquatic 415 ecosystems. Environmental Reviews, 26. doi:10.1139/er-2017-0040

416 Syväranta, J., Lensu, A., Marjomäki, T. J., Oksanen, S., \& Jones, R. I. (2013). An empirical 417 evaluation of the utility of convex hull and standard ellipse areas for assessing population niche 418 widths from stable isotope data. PLOS ONE, 8(2), e56094. doi:10.1371/journal.pone.0056094

419 Tanentzap, A. J., B. W. Kielstra, G. M. Wilkinson, M. Berggren, N. Craig, P. A. del Giorgio, J. 420 Grey, J. M. Gunn, S. E. Jones, J. Karlsson, C. T. Solomon, \& M. L. Pace, (2017) Terrestrial support 421 of lake food webs: Synthesis reveals controls over cross-ecosystem resource use. Science Advances 4223 , e1601765.

423 Teodoru, C. R., Nyoni, F. C., Borges, A. V., Darchambeau, F., Nyambe, I., \& Bouillon, S. (2015). 424 Dynamics of greenhouse gases $\left(\mathrm{CO}_{2}, \mathrm{CH}_{4}, \mathrm{~N}_{2} \mathrm{O}\right)$ along the Zambezi River and major tributaries, 425 and their importance in the riverine carbon budget. Biogeosciences, 12(8), 2431-2453. 426 doi:10.5194/bg-12-2431-2015 
427 Thorp, J. H. (1991). Ecology and classification of North American freshwater invertebrates.

428 Academic Press.

429 Vander Zanden, H. B., Soto, D. X., Bowen, G. J., \& Hobson, K. A. (2016). Expanding the isotopic 430 toolbox: applications of hydrogen and oxygen stable isotope ratios to food web studies. Frontiers 431 in Ecology and Evolution, 4. doi:10.3389/fevo.2016.00020

432 Villéger, S., Mason, N. W. H., \& Mouillot, D. (2008). New multidimensional functional diversity 433 indices for a multifaceted framework in functional ecology. Ecology, 89(8), 2290-2301. 434 doi:10.1890/07-1206.1

435 Wolf, J. M., Johnson, B., Silver, D., Pate, W., \& Christianson, K. (2016). Freezing and 436 fractionation: effects of preservation on carbon and nitrogen stable isotope ratios of some limnetic 437 organisms. Rapid Communications in Mass Spectrometry, 30(5), 562-568. doi:10.1002/rcm.74 
Figure 1

Boxplots of $\mathrm{pCO}_{2}$ concentrations in water samples (expressed in supersaturation ratio, SR) and DIC- ${ }^{13} \mathrm{C}$ values (expressed in \%o) for the five waterfall sites sampled in early May and late June 2016.

Grey symbols represent below-waterfall samples, whereas white symbols correspond to above-waterfall sites.

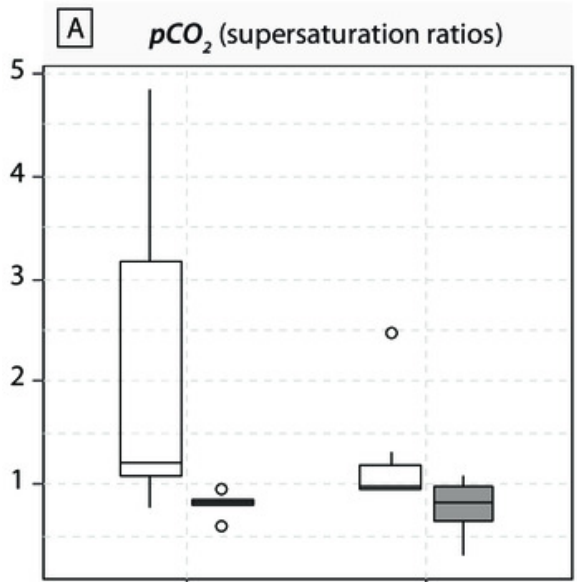

Early May

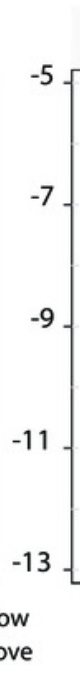

B

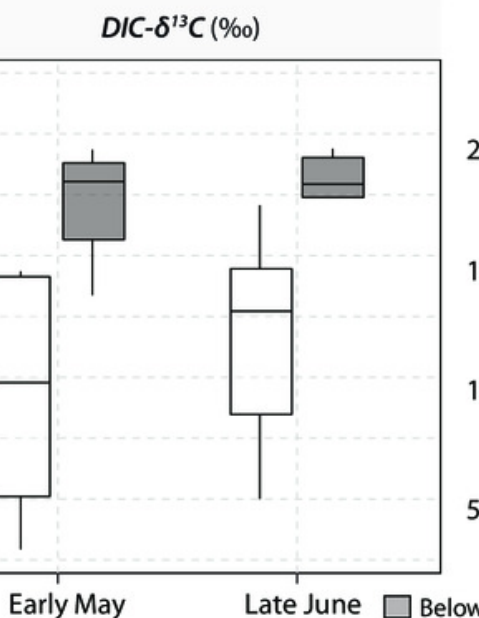

Early May
C

Temperature $\left({ }^{\circ} \mathrm{C}\right)$

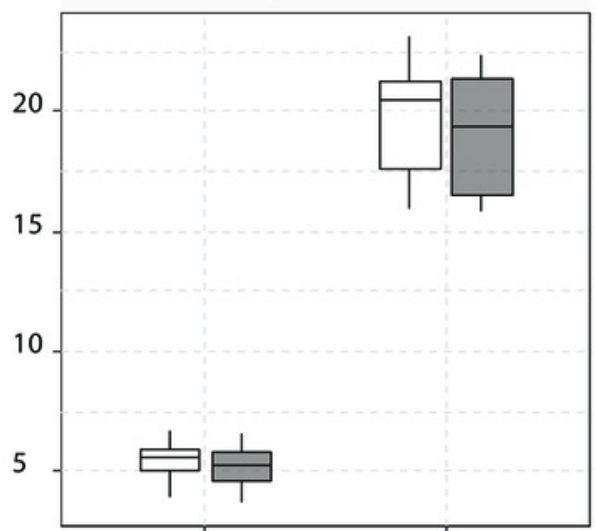

Early May

Late June $\square$ Below 
Figure 2

NMDS ordination biplot of invertebrate communities at waterfall sites based on Bray-Curtis index (presence/absence).

Waterfall sites are abbreviated to the first four letters, and each pair of sampling site are linked with a dotted black line.
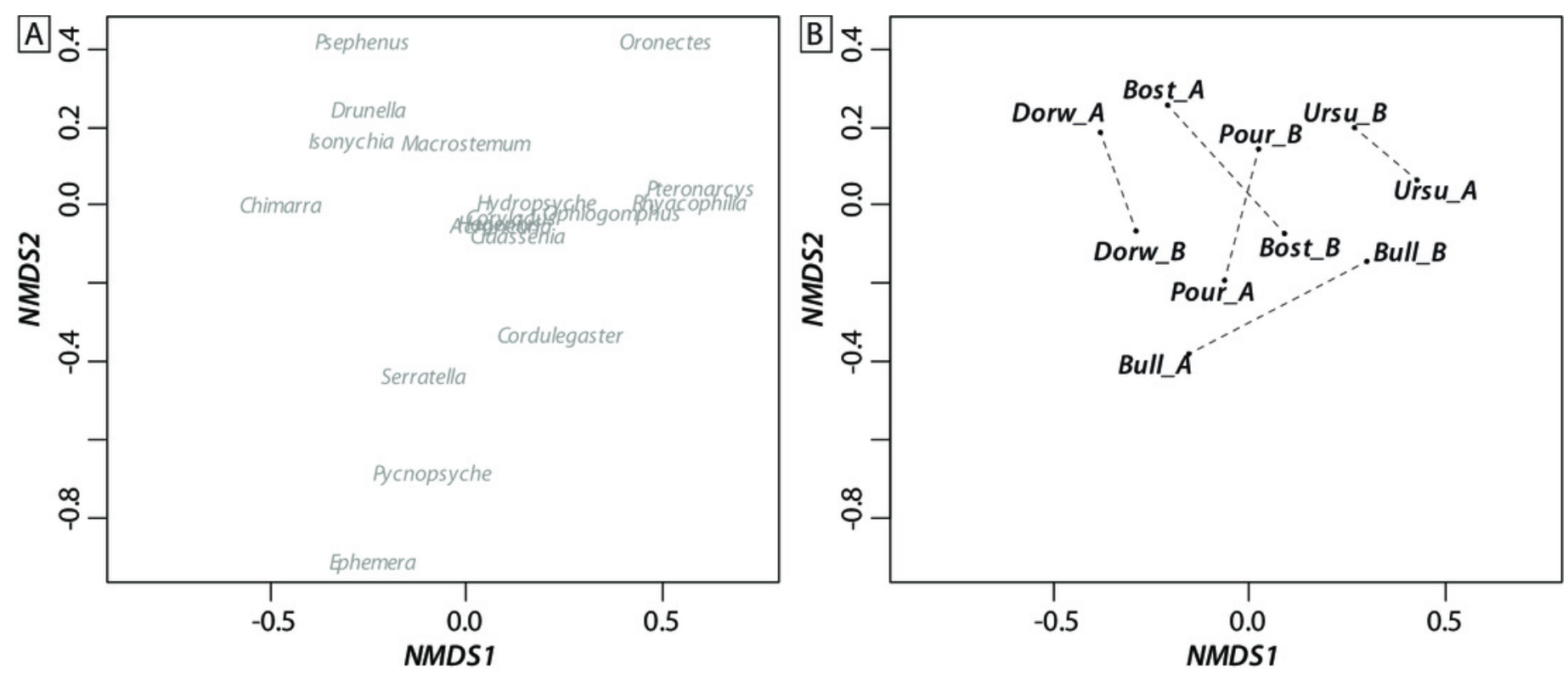
Figure 3

Carbon $\left(\delta^{13} \mathrm{C}\right)$ and nitrogen stable isotopic ratios $\left(\delta^{15} \mathrm{~N}\right)$ of invertebrate communities collected in the five waterfall sites.

Each point on the graph represents the mean value of 2 - 7 individuals of each species. Error bars are omitted for simplicity.

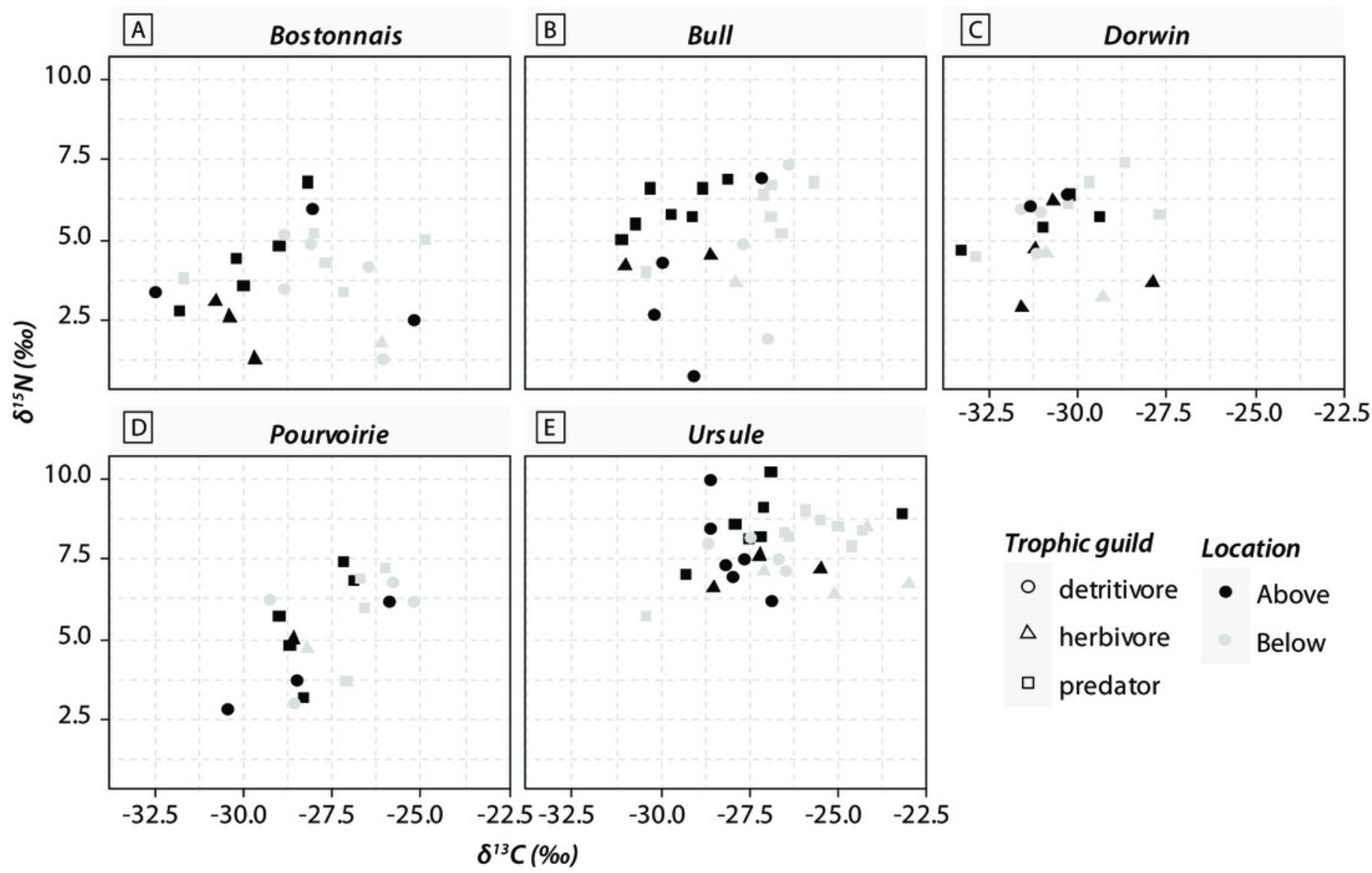


Figure 4

Boxplots of trophic guilds $\delta^{15} \mathrm{~N}$ values (expressed in \%o) for the five waterfall sites.

Grey symbols represent below-waterfall samples, whereas white symbols correspond to above-waterfall sites. None of the relationships were significant ( $t$-test; $p$-value $>0.05$ ).
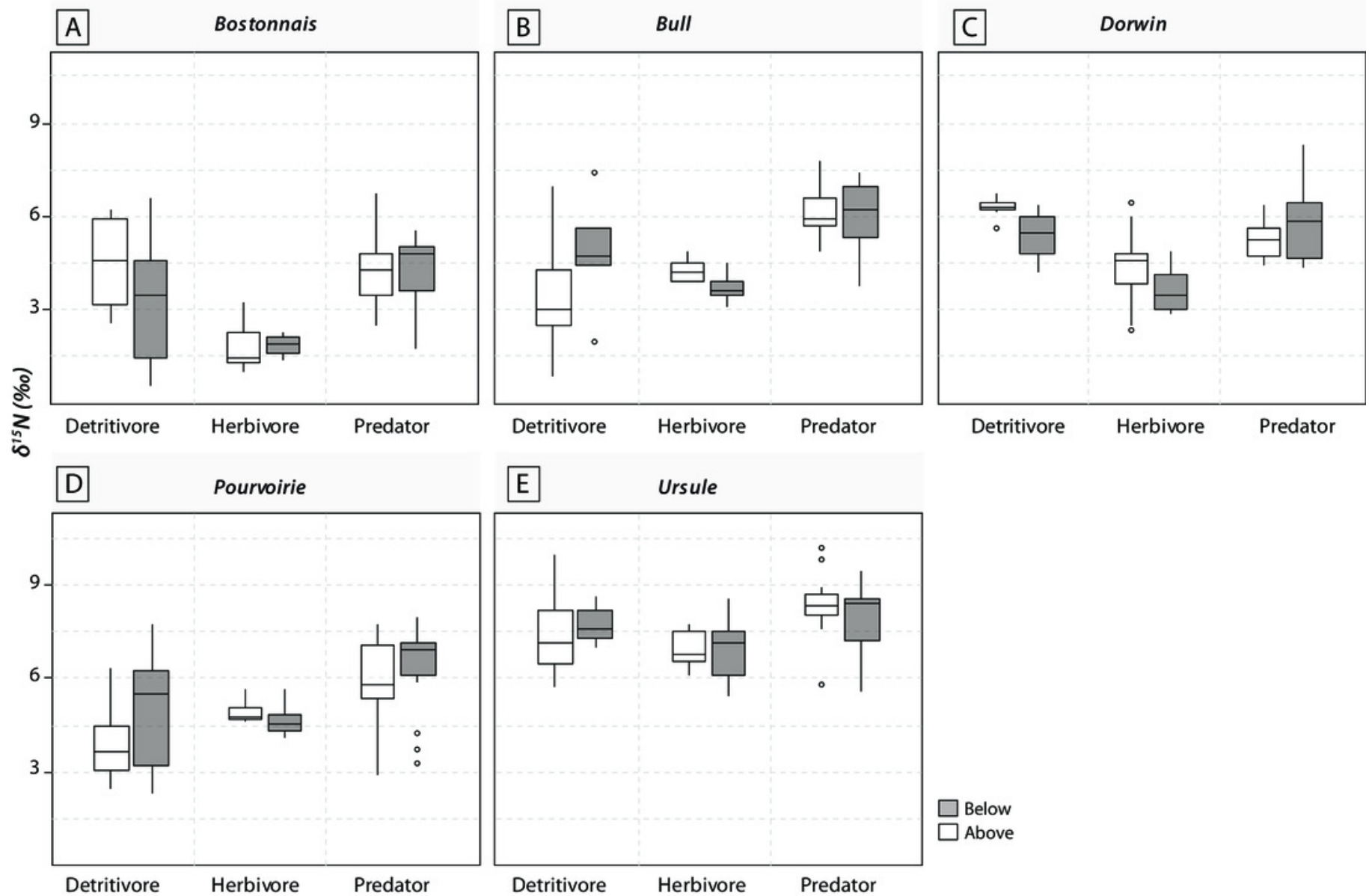

$\begin{array}{ll}\text { Detritivore } & \text { Herbivo } \\ \text { E } & \text { Ursule }\end{array}$

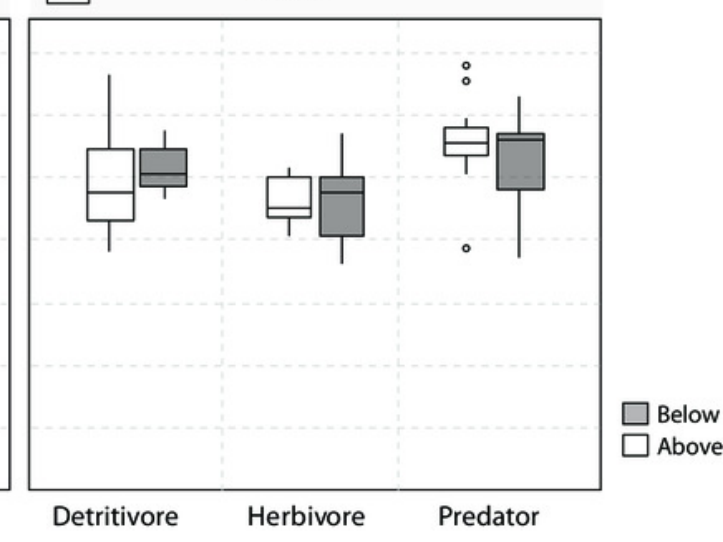


Figure 5

Changes in $\delta^{13} \mathrm{C}$ values for DIC and consumers belonging to different trophic guilds between above- and below-waterfall samples (with $\Delta \delta^{13} C=\delta^{13} C_{\text {below }}-\delta^{13} C_{\text {above }}$ ).

Trophic guilds are abbreviated to the first four letters (e.g., Herbivore becomes "Herb").
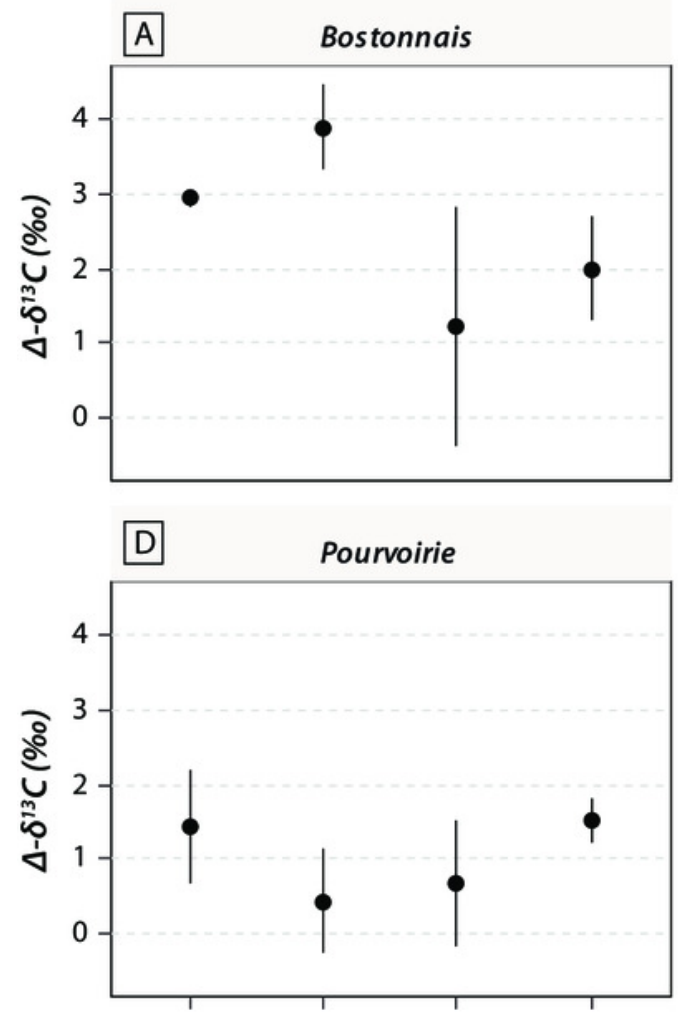

DIC Herbivore Detritivore Predator

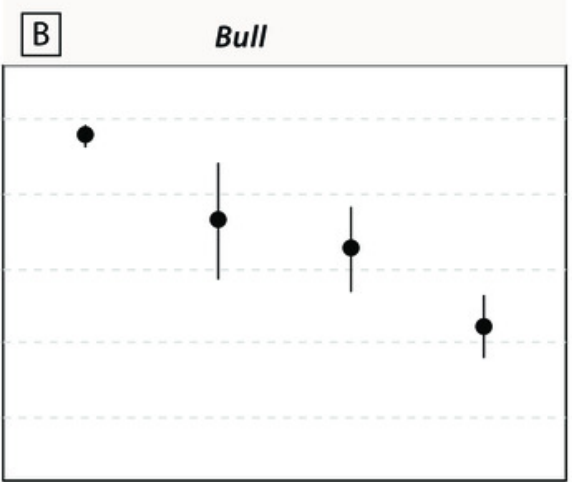

E

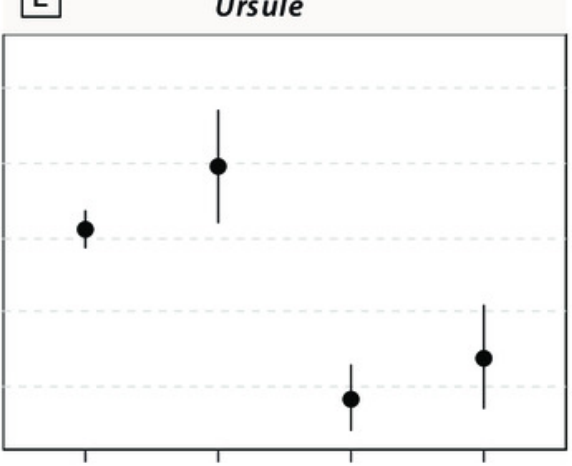

DIC Herbivore Detritivore Predator

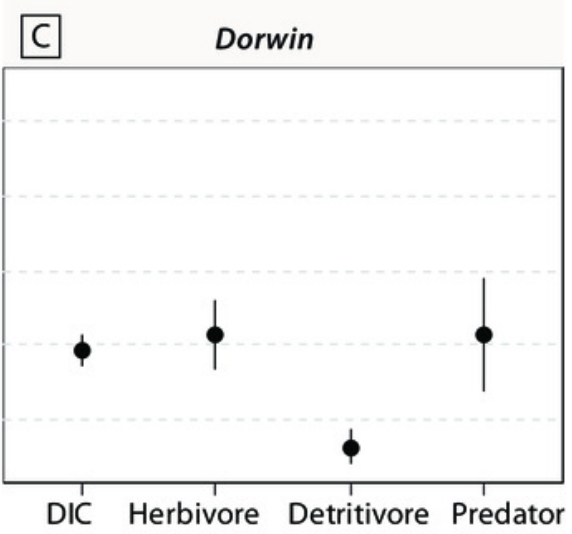


Figure 6

Barplot comparing isotopic functional indices and DIC- $\delta^{13} \mathrm{C}$ values obtained from above$v s$. below-waterfall sites of the five streams and rivers.

Each barplot indicates the difference in each IFI value between above- vs. below-waterfall sites ( $\Delta=$ above - below), and colours refer to the direction of changes (black = positive; grey $=$ negative) .

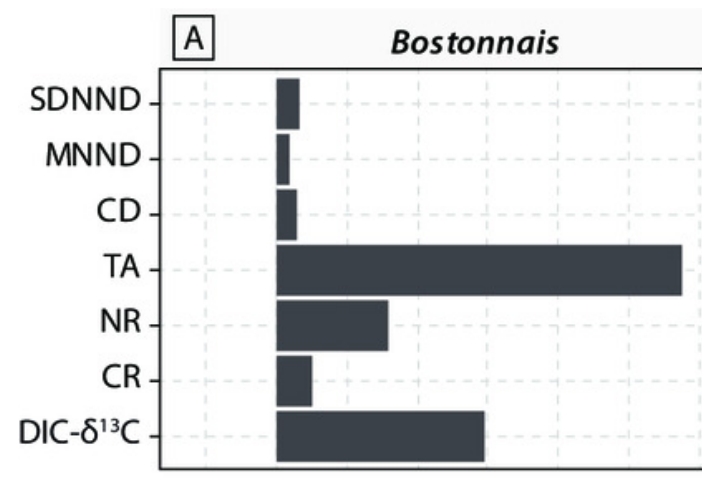

$B$

Bull
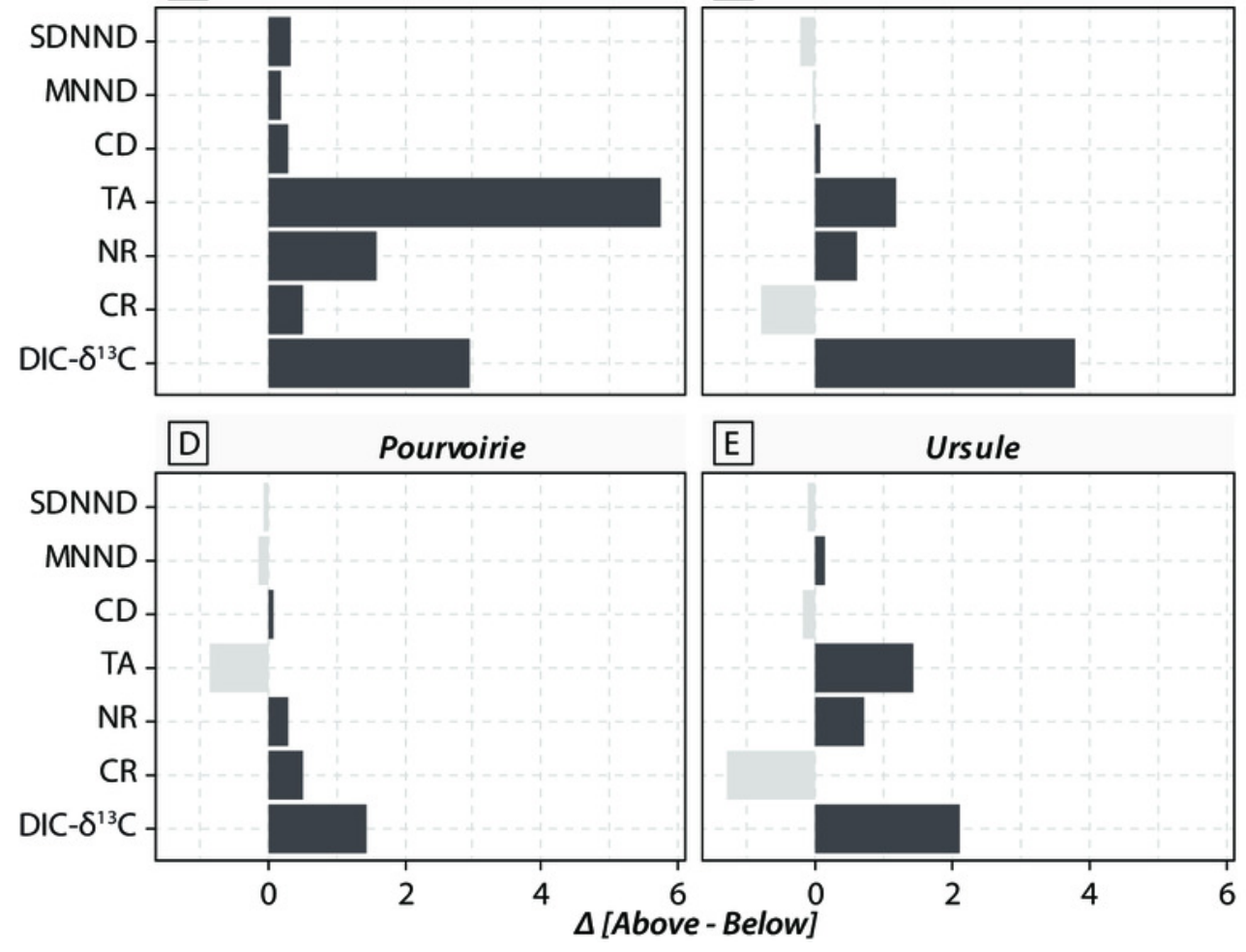

C Dorwin

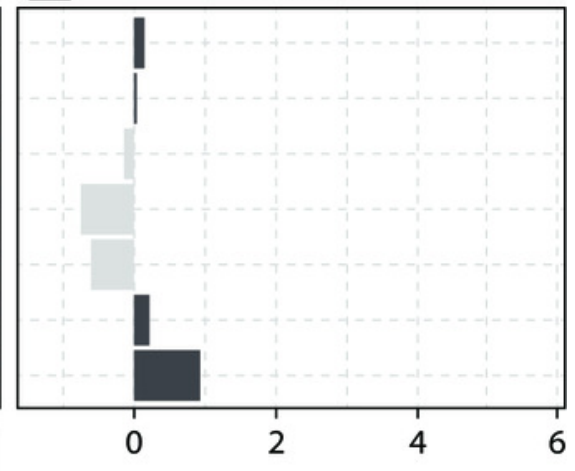


Figure 7

(A) Factorial map of the principal component analysis (PCA) performed on isotopic functional indices (PCA2 versus PCA1). (B) Correlation circle representing isotopic functional indices' contributions to the first two axes of the PCA.

Symbols refer to rivers, whereas colours refer to sampling locations. DIC- $\delta^{13} \mathrm{C}$ (grey arrow) has been added to the correlation circle as a passive variable.
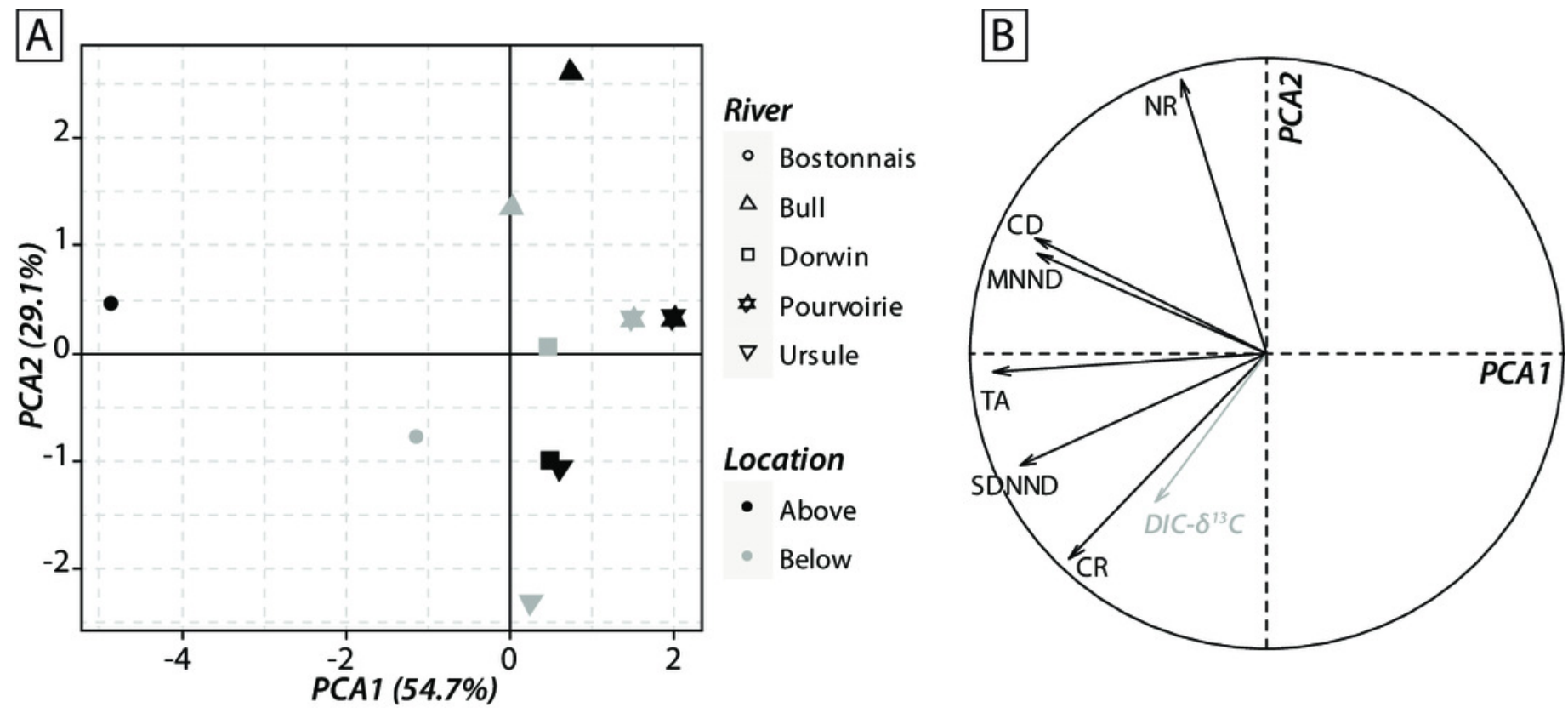


\section{Table $\mathbf{1}$ (on next page)}

Taxonomic list of macroinvertebrate collected in the sampling sites.

Specimens were classified into different functional groups according to their theoretical feeding behaviours: herbivore, detritivore, and predator (Thorp and Covich, 1991; Merritt and Cummins, 1996). Waterfall systems are abbreviated to the first four letters. 
1 Table 1 Taxonomic list of macroinvertebrate collected in the sampling sites (1/0 refer 2 presence/absence). Specimens were classified into different functional groups according to their

3 theoretical feeding behaviours: herbivore, detritivore, and predator (Thorp and Covich, 1991; 4 Merritt and Cummins, 1996). Waterfall systems are abbreviated to the first four letters. A refers 5 above-waterfall sites and B to below-waterfall sites. 


\begin{tabular}{|c|c|c|c|c|c|c|c|c|c|c|c|c|c|}
\hline \multirow{2}{*}{ Order } & \multirow{2}{*}{ Family } & \multirow{2}{*}{ Genus } & \multirow{2}{*}{$\begin{array}{l}\text { Trophic } \\
\text { guild }\end{array}$} & \multicolumn{2}{|c|}{ Bost } & \multicolumn{2}{|c|}{ Bull } & \multicolumn{2}{|c|}{ Dorw } & \multicolumn{2}{|c|}{ Pour } & \multicolumn{2}{|c|}{ Ursu } \\
\hline & & & & $\mathbf{A}$ & B & $\mathbf{A}$ & B & $\mathbf{A}$ & B & $\mathbf{A}$ & B & $\mathbf{A}$ & B \\
\hline Crustacea & Cambaridae & Orconectes & Detritivore & 1 & 0 & 0 & 0 & 0 & 0 & 1 & 1 & 0 & 0 \\
\hline Ephemeroptera & Ephemerellidae & Serratella & Detritivore & 0 & 1 & 1 & 0 & 0 & 1 & 0 & 0 & 1 & 0 \\
\hline Plecoptera & Pteronarcyidae & Pteronarcys & Detritivore & 0 & 0 & 0 & 1 & 0 & 0 & 1 & 1 & 1 & 1 \\
\hline Trichoptera & Hydropsychidae & Hydropsyche & Detritivore & 1 & 1 & 1 & 1 & 1 & 1 & 1 & 1 & 1 & 1 \\
\hline Trichoptera & Hydropsychidae & Macrostemum & Detritivore & 1 & 1 & 0 & 0 & 1 & 1 & 0 & 1 & 1 & 1 \\
\hline Trichoptera & Limnephilidae & Pycnopsyche & Detritivore & 0 & 0 & 1 & 0 & 0 & 0 & 0 & 0 & 1 & 0 \\
\hline Coleoptera & Psepheridae & Psephenus & Herbivore & 0 & 0 & 0 & 0 & 1 & 0 & 0 & 0 & 0 & 1 \\
\hline Ephemeroptera & Ephemerellidae & Drunella & Herbivore & 1 & 0 & 0 & 0 & 1 & 0 & 0 & 0 & 1 & 1 \\
\hline Ephemeroptera & Heptageniidae & Epeorus & Herbivore & 1 & 1 & 1 & 1 & 1 & 1 & 1 & 1 & 1 & 1 \\
\hline Ephemeroptera & Ephemeridae & Ephemera & Herbivore & 0 & 0 & 1 & 0 & 0 & 0 & 0 & 0 & 0 & 0 \\
\hline Ephemeroptera & Oligoneuriidae & Isonychia & Herbivore & 1 & 0 & 0 & 0 & 1 & 1 & 0 & 0 & 1 & 1 \\
\hline Megaloptera & Corylaridae & Coryladus & Predator & 0 & 1 & 1 & 0 & 1 & 1 & 1 & 1 & 1 & 1 \\
\hline Odonata & Aeshnidae & Boyeria & Predator & 1 & 1 & 1 & 1 & 1 & 1 & 1 & 1 & 1 & 1 \\
\hline Odonata & Cordulegastridae & Cordulegaster & Predator & 0 & 0 & 1 & 1 & 0 & 0 & 0 & 0 & 1 & 1 \\
\hline Odonata & Gomphidae & Hagenius & Predator & 0 & 0 & 0 & 0 & 0 & 0 & 0 & 0 & 1 & 1 \\
\hline Odonata & Gomphidae & Ophiogomphus & Predator & 1 & 0 & 1 & 1 & 0 & 0 & 1 & 0 & 0 & 1 \\
\hline Plecoptera & Perlidae & Acroneuria & Predator & 1 & 1 & 1 & 1 & 1 & 1 & 1 & 0 & 1 & 1 \\
\hline Plecoptera & Perlidae & Claassenia & Predator & 1 & 1 & 1 & 1 & 0 & 1 & 0 & 1 & 1 & 1 \\
\hline Trichoptera & Philopotamidae & Chimarra & Predator & 1 & 0 & 1 & 0 & 1 & 1 & 0 & 0 & 0 & 0 \\
\hline Trichoptera & Rhyacophilidae & Rhyacophilia & Predator & 0 & 1 & 0 & 1 & 0 & 0 & 1 & 1 & 1 & 1 \\
\hline
\end{tabular}

